DOI: 10.12731/2227-930X-2021-11-3-83-88

УДК 625.711.6

\title{
ОЦЕНКА КАЧЕСТВА УСЛОВИЙ ДВИЖЕНИЯ ПЕШЕХОДОВ ПО ТРОТУАРАМ
}

\section{Галымев А.Б.}

Важнейшей задачей городской транспортной политики является обеспечение удобства и безопасности пешеходного движения. Пешеходы должны перемещаться с удобной для себя скоростью, не мешая друг другу. А для этого необходимо создавать качественные тротуары. В данной статье по специильной методике производится оченка уровня комфорта движения пешеходов по ряду улии в городе Красногорске.

Ключевые слова: пешеход; пешеходное движение; тротуар; Индекс уровня комфорта пешеходов

\section{ASSESSMENT OF THE QUALITY OF PEDESTRIAN TRAFFIC CONDITIONS ON SIDEWALKS}

\section{Galyshev A.B.}

The most important task of the city's transport policy is to ensure the convenience and safety of pedestrian traffic. Pedestrians should move at a convenient speed, without interfering with each other. And for this it is necessary to create high-quality sidewalks. In this article, a special method is used to assess the level of comfort of pedestrian traffic on a number of streets in the city of Krasnogorsk.

Keywords: pedestrian; pedestrian traffic; sidewalk; Pedestrian Comfort Level

\section{Введение}

Единая система пешеходных коммуникаций является необходимой составной частью транспортной системы любого города. При этом эффективность ее функционирования определяется, прежде все- 
го, двумя критериями: безопасностью и удобством [1]. Пешеходы являются наиболее уязвимыми участниками дорожного движения. Для них представляют опасность не только автомобили, но даже велосипедисты [2]. Но даже если безопасность пешеходной дорожки (тротуара) обеспечена должным образом, остается еще важная задача по обеспечению удобства движения. И одной из ее основных составляющих является контроль плотности пешеходных потоков.

\section{Материалы и методы исследования}

Для оценки уровня комфорта передвижения пешеходов по тротуару необходимо рассчитать Индекс уровня комфорта пешеходов (анг. Pedestrian Comfort Level, PCL). Он базируется на величине плотности наблюдаемого на данной улице пешеходного потока [3]. Для его оценки необходимо разбить улицу на некоторое количество участков, выделив наиболее характерные сечения улицы (пикеты). Эти пикеты должны содержать объекты, препятствующие движению, или располагаться в местах расширения или сужения тротуара. Таким образом можно максимально объективно оценить качество перемещения пешеходов по всему тротуару в целом.

Индекс PCL, чел./(м·мин), рассчитывается для каждого пикета по формуле (1). Это позволяет анализировать качество перемещения пешеходов как в отдельных точках, так и на протяжении всего тротуара в целом.

$$
P C L=\frac{F_{m(p)}}{60 \cdot W_{c p}},
$$

где $\mathrm{W}_{\mathrm{cp}}$ - чистая ширина прохода, $\mathrm{m} ; \mathrm{F}_{\mathrm{m}(\mathrm{p})}$ - средняя или пиковая интенсивность (плотность) пешеходного потока, чел./с.

Величина $\mathrm{W}_{\mathrm{cp}}$ как правило определяется отдельно для каждого пикета экспериментальным путем. Плотность $\mathrm{F}_{\mathrm{m}(\mathrm{p})}$ определяется по формуле

$$
F_{m(p)}=\frac{3600 \cdot N_{\text {total }(p)}}{T_{s} \cdot n_{s(p)}}
$$

где $\mathrm{N}_{\text {total }}$ - общее количество пешеходов, прошедшее через «виртуальные ворота» за общее время всех измерений (или за час пик), 
чел.; $\mathrm{T}_{\mathrm{s}}$ - время одного измерения, c; $\mathrm{n}_{\mathrm{s}}$ - общее количество измерений (или в течение часа пик).

В зависимости от величины PCL условия движения пешеходов в сечении данного пикета относятся к одной из категорий:

A-, A, A+ - данные категории обеспечивают максимальный уровень комфорта для движения пешеходов независимо от тип территории.

B-, В, В + - данные категории обеспечивают минимальный уровень комфорта для движения пешеходов по большинству типов улиц. Тип В- считается некомфортным для главных улиц или туристических маршрутов.

$\mathrm{C}-, \mathrm{C}, \mathrm{C}+$ - данные категории обеспечивают минимальный уровень комфорта для движения пешеходов в деловых районах и транспортно-пересадочных зонах. Для селитебных районов такие условия считаются некомфортными, а для главных улиц - неприемлемыми.

$\mathrm{D}, \mathrm{E}$ - данные категории не обеспечивают комфортных условий для движения пешеходов, создавая «предзаторовую» ситуацию. Свобода маневра отсутствует. Пешеходам желательно искать обходные пути, поскольку условия движения могут стать не только неудобными, но и опасными.

\section{Результаты исследования}

В таблице 1 показаны результаты оценки уровня комфорта пешеходов на примере семи улиц города Красногорска.

Таблиц̧а 1.

Результаты оценки уровня комфорта пешеходного движения

\begin{tabular}{|l|c|c|c|c|c|}
\hline Местоположение территории & $\begin{array}{c}\text { Тип тер- } \\
\text { ритории }\end{array}$ & $\begin{array}{c}\text { Зна- } \\
\text { чение } \\
\mathrm{W}_{\mathrm{cp}}, \mathrm{M}\end{array}$ & $\begin{array}{c}\text { Зна- } \\
\text { чение } \\
\mathrm{F}_{\mathrm{m}(\mathrm{p})} \\
\text { чел./c }\end{array}$ & $\begin{array}{c}\text { Значе- } \\
\text { ние PCL, } \\
\text { чел./(м-- } \\
\text { мин) }\end{array}$ & $\begin{array}{c}\text { Катего- } \\
\text { рия ка- } \\
\text { чества }\end{array}$ \\
\hline Красногорский бульвар, 28 & $\begin{array}{c}\text { селитеб- } \\
\text { ный рай- } \\
\text { он }\end{array}$ & 2,5 & 880 & 5,87 & $\mathrm{~A}$ \\
\hline $\begin{array}{l}\text { Международная улица (Мя- } \\
\text { кинино) }\end{array}$ & $\begin{array}{c}\text { деловой } \\
\text { район }\end{array}$ & 2,5 & 2513 & 16,75 & $\mathrm{~B}-$ \\
\hline
\end{tabular}


Окончание табл. 1.

\begin{tabular}{|l|c|c|c|c|c|}
\hline $\begin{array}{l}\text { улица Братьев Горожанки- } \\
\text { ных, 22 }\end{array}$ & $\begin{array}{c}\text { селитеб- } \\
\text { ный рай- } \\
\text { он }\end{array}$ & 1,9 & 170 & 1,49 & $\mathrm{~A}+$ \\
\hline Комсомольская улица 41 & $\begin{array}{c}\text { Главная } \\
\text { улица }\end{array}$ & 3,0 & 528 & 2,93 & $\mathrm{~A}+$ \\
\hline улица Маяковского, 16 & $\begin{array}{c}\text { Главная } \\
\text { улица }\end{array}$ & 3,0 & 480 & 2,67 & $\mathrm{~A}+$ \\
\hline Павшинская улица, 27 & $\begin{array}{c}\text { Главная } \\
\text { улица }\end{array}$ & 1,06 & 390 & 6,2 & $\mathrm{~A}-$ \\
\hline улица Строительная, 4 & $\begin{array}{c}\text { Сели- } \\
\text { тебный } \\
\text { район }\end{array}$ & 1,3 & 115 & 1,47 & $\mathrm{~A}+$ \\
\hline
\end{tabular}

\section{Обсуждение}

Результаты исследования показывают, что условия движения пешеходов на шести из семи рассматриваемых улиц могут быть оценены как комфортные, а в седьмом случае как приемлемые. Таким образом, можно утверждать, что пешеходная инфраструктура города Красногорска в целом является качественно и хорошо справляется со своими задачами независимо от типа территории. Тем не менее, пример района Мякинино показывает, что резкий рост транспортной мобильности населения, в данном случае связанный с открытием станции метро, может привести к значительному ухудшению условий движения пешеходов. Поэтому в будущем, по мере совершенствования транспортной и жилищной инфраструктуры города Красногорска, предлагается продолжить осуществлять оценку изменений уровня комфорта пешеходов по данной методике.

\section{Заключение}

В данной статье рассмотрена методика оценки качества пешеходной инфраструктуры. Исследования проводились на семи улицах города Красногорска, принадлежащих к разным типам городской территории. Результаты оценки показали, что данная методика вполне пригодна для оценки уровня комфорта пешеходов в условиях Подмосковья. При этом, согласно результатам исследо- 
ваний, на всех рассматриваемых улицах наблюдаются комфортные или приемлемые условия для движения пешеходов.

Информация о конфликте интересов. Автор заявляет об отсутствии конфликта интересов.

Информация о спонсорстве. Исследование не имело спонсорской поддержки.

\section{Список литературы}

1. Дмитриев А.С. Формирование критериев комфортности пешеходного движения в транспортно-пересадочных узлах // Промышленное и гражданское строительство. 2018. № 7. С. 61-66.

2. О необходимости развития велосипедного транспорта в крупных городах России / Ю. В. Трофименко, А. Н. Сова, В. В. Буренин, А. Б. Галышев // Автомобильный транспорт. 2014. № 3. C. 70-74.

3. Pedestrian Comfort Level Guidance for London. Guidance Document. First Edition. Transport for London, 2010.

\section{References}

1. Dmitriev A.S. Formirovanie kriterev komfortnosti peshehodnogo dvizheniya $\mathrm{v}$ transportno-peresadochnyh uzlah [Formation of criteria for the comfort of pedestrian traffic in transport hubs]. Promyshlennoe i grazhdanskoe stroitel'stvo, 2018, no. 7, pp. 61-66.

2. Trofimenko Yu.V. O neobhodimosti razvitiya velosipednogo transporta $\mathrm{v}$ krupnyh gorodah Rossii [On the need for the development of bicycle transport in major cities of Russia]. Avtomobil 'nyi transport, 2014, no. 3, pp. 70-74.

3. Pedestrian Comfort Level Guidance for London. Guidance Document. First Edition. Transport for London, 2010.

\section{ДАННЫЕ ОБ АВТОРЕ}

Галышев Алексей Борисович, старший преподаватель, кандидат технических наук, без ученого звания 
Московский автомобильно-дорожный государственный технический университет (МАДИ)

Ленинградский проспект, 64, г. Москва, 125319, Российская Федерация

alexborr@yandex.ru

\section{DATA ABOUT THE AUTHOR}

Alexey B. Galyshev, Senior Lecturer, Ph.D.

Moscow Automobile and Road Construction State Technical University (MADI)

64, Leningradsky prospect, Moscow, 125319, Russian Federation

alexborr@yandex.ru

ORCID: 0000-0002-1328-1142 